\title{
Differences in pronucleus formation and first cleavage following in vitro fertilization between pig oocytes matured in vivo and in vitro
}

\author{
J. Laurincik ${ }^{1}$, D. Rath ${ }^{2 *}$, and H. Niemann ${ }^{2}$ \\ ${ }^{1}$ Research Institute of Animal Production, Hlohovska 2, 94992 Nitra, Slovak Republic; and ${ }^{2}$ Institut für \\ Tierzucht und Tierverhalten (FAL) Mariensee, 31535 Neustadt, Germany
}

To elucidate the developmental differences occurring after in vitro fertilization (IVF) of pig oocytes matured either in vitro $(n=1934)$ or in vivo $(n=1128)$, the present experiment investigated the morphological changes from penetration to the two-cell stage. Oocytes were examined every $2-4 \mathrm{~h}$ from 2 to $32 \mathrm{~h}$ after in vitro insemination to study sperm penetration, male and female pronucleus formation, synkaryosis and first cleavage. The penetration rate was significantly higher $(P<0.05)$ for in vivo matured oocytes $(69.8 \%)$ than for in vitro matured oocytes $(35.0 \%)$. Penetration of spermatozoa into the ooplasm was first recorded $6 \mathrm{~h}$ (in vitro matured oocytes) and $4 \mathrm{~h}$ (in vivo matured oocytes) after addition of the spermatozoa to the oocytes. For both in vivo and in vitro matured oocytes, $2 \mathrm{~h}$ were required for sperm head decondensation. However, maximum sperm head decondensation occurred $2 \mathrm{~h}$ later in in vitro matured oocytes. Within $6 \mathrm{~h}, 41.7 \pm 5.6 \%$ of the in vivo matured oocytes had completed second meiotic division, whereas only $20.8 \pm 6.5 \%$ of the in vitro matured oocytes reached this developmental stage $(P<0.01)$. For in vitro matured oocytes, male pronucleus formation was retarded $2-4 \mathrm{~h}$ after onset of insemination and development of the female pronucleus was enhanced compared with in vivo matured oocytes. Synchronized opposing pronuclei were observed $14 \mathrm{~h}$ after insemination in in vitro matured oocytes and after $8 \mathrm{~h}$ in in vivo matured oocytes. Synkaryosis was first observed at 16 and $18 \mathrm{~h}$ in in vivo and in vitro matured oocytes, respectively. First cleavage was observed $32 \mathrm{~h}$ (in vitro matured oocytes) and $28 \mathrm{~h}$ (in vivo matured oocytes) after insemination. It is concluded that under our IVF conditions, oocytes matured in vitro display lower penetration and cleavage rates and asynchronous pronucleus development, as well as delayed cleavage, compared with oocytes matured in vivo.

\section{Introduction}

Pig oocytes matured in vivo and obtained by aspiration from pre-ovulatory follicles can be fertilized in vitro using fresh boar semen (Cheng ef al., 1986; Yoshida, 1987; Yoshida et al., 1990; Rath, 1992) or frozen-thawed epididymal spermatozoa (Nagai et al., 1988). Similarly, it has been shown that in vitro matured pig oocytes can be fertilized in vitro (Mattioli et al., 1988a; Yoshida et al., 1993). However, polyspermy (Nagai et al., 1984; Cheng, 1985; Mattioli et al., 1988a) and irregular male pronucleus formation (Motlik and Fulka, 1974; Nagai et al., 1984; Mattioli et al., 1988a; Naito et al., 1988; Wang et al., 1991) perturb early embryonic development and limit potential practical applications of IVF technology. In vivo, communication between cumulus cells and oocytes in pig (Motlik and Fulka, 1986; Mattioli et al., 1988a, b) and bovine (Laurincik et al., 1992a, b) cumulus-oocyte complexes is required for proper maturation of the respective oocytes and plays a crucial role in regular early embryonic development (Mattioli et al.,

*Correspondence.

Received 17 February 1994. 1988b). In vitro, inappropriate culture conditions lead to an abnormal distribution of the cortical granules (Mattioli et al., 1988a; Hyttel et al., 1988a; Nagai et al., 1988; Nagai and Moor, 1990; Yoshida et al., 1990). The reduced or delayed release of specific substances from the granules is thought to be responsible for the establishment of an incomplete zona block (Cran and Cheng, 1986).

The influence of media on nuclear maturation of pig oocytes cultured in vitro has been reported by Tsafriri and Channing (1975), Sato et al. (1977), Racowsky and McGaughey (1982), Eng et al. (1986) and Yoshida et al. (1989). However, culture conditions for a complete and synchronous maturation of both nuclear and cytoplasmic compartments in pig oocytes have only partly been explored (Tsafriri et al., 1976; Meinecke and Meinecke-Tillmann, 1979; Motlik and Fulka, 1986; Moor et al., 1990; Moor, 1993). Low rates of male pronucleus formation in pig oocytes matured and fertilized in vitro persist (Iritani et al., 1978; Nagai et al., 1984; Mattioli et al., 1988b; Yoshida et al., 1990).

Follicular fluid has been demonstrated to have profound effects on male pronucleus formation (Naito et al., 1988; Naito and Toyoda, 1992), as well as follicular cells (Mattioli et al., 
1988b; Zheng and Sirard, 1992; Ding and Foxcroft, 1992), LH (Mattioli et al., 1991), pregnant mares' serum gonadotrophin (PMSG), hCG and oestradiol (Funahashi and Day, 1993), and glutathione and cysteine (Yoshida et al., 1992b, 1993; Naito and Toyoda, 1992). Similar findings were observed when cumulus cells surrounded the oocyte during fertilization (Wang et al., 1991; Niwa, 1993).

Analysis of pig oocytes within the first $10 \mathrm{~h}$ after in vitro fertilization showed that sperm penetration begins $3 \mathrm{~h}$ after insemination. This was followed by sperm head decondensation and nuclear maturation up to anaphase II in $50 \%$ of penetrated oocytes within $5 \mathrm{~h}$ after insemination. Both male and female pronuclei were present $8 \mathrm{~h}$ after insemination (Ding et al., 1992).

The objective of the present study was to compare the sequence of morphological development of both male and female pronuclei during the complete first embryonic cell cycle after in vitro fertilization of pig cumulus-oocyte complexes matured either in vivo or in vitro.

\section{Materials and Methods}

\section{Sources of oocytes}

In vitro matured oocytes. Ovaries were collected from prepubertal gilts at a local abattoir and within $\mathrm{Ih}$ after slaughter were transported at room temperature to the laboratory. Follicles $2-5 \mathrm{~mm}$ in diameter were punctured; cumulusoocyte complexes were collected in modified Dulbecco's phosphate buffered saline (PBS); and the aspirated fluid was examined at $\times 10-60$ magnification. Cumulus-oocyte complexes were washed once and then placed into preincubated $\left(39^{\circ} \mathrm{C}, 5 \% \mathrm{CO}_{2}\right.$ in air, humidified atmosphere) TCM 199 (Sigma, St Louis, MO) supplemented with $I \mu g$ purified FSH $\mathrm{ml}^{-1}$ (UCB, l'Alleude), $0.1 \mathrm{mg}$ L-glutamine $\mathrm{ml}^{-1}$ (Sigma), $25 \mathrm{mmol} \mathrm{Hepes} \mathrm{l}^{-1}$ (Sigma), 10\% new born calf serum (NBCS) (Boehringer, Mannheim) and $5 \mathrm{mg}$ Gentamicin $\mathrm{ml}^{-1}$ (Sigma) (maturation medium). Oocytes (five per microdrop) with firmly attached cumulus cell layers and an evenly granulated cytoplasm were selected for cultivation in maturation medium using $50 \mu \mathrm{l}$ microdrops covered with preincubated $\left(39^{\circ} \mathrm{C}, 5 \% \mathrm{CO}_{2}\right.$ in air, and humidified atmosphere) silicone oil. Forty-eight hours later cumulus-oocyte complexes were evaluated for cumulus expansion and integrity of ooplasm (Rath, 1992).

In vivo matured oocytes. Prepubertal gilts were stimulated with 1500 iu PMSG (Intergonan: Vemie, Kempen), followed by 500 iu hCG (Ekluton: Vemie) $72 \mathrm{~h}$ later. The gilts were slaughtered to collect the oocytes $38 \mathrm{~h}$ thereafter. Follicles of 5-10 $\mathrm{mm}$ diameter were punctured and matured cumulusoocyte complexes were preincubated for $2 \mathrm{~h}$ in TCM 199 supplemented with $0.1 \mathrm{mg} \mathrm{L-glutamine} \mathrm{ml}^{-1}, 10 \%$ fetal calf serum (FCS) (Boehringer, Mannheim) and $10 \mu \mathrm{g}$ dibekacin sulfate (Sigma) (Rath, 1992).

\section{Semen preparation}

Sperm rich fractions $(20-30 \mathrm{ml})$ of ejaculates were collected from two German Landrace boars of proven fertility into prewarmed $\left(38^{\circ} \mathrm{C}\right)$ collection tubes by the gloved hand method. Immediately after collection, samples from both boars were mixed and diluted with Androhep extender (Minitüb, Tiefenbach) $1: 1(\mathrm{v}: \mathrm{v})$ and treated for capacitation as described by Rath (1992). Briefly, semen samples were centrifuged, at $550 \mathrm{~g}$ for $5 \mathrm{~min}$, twice and the pellets were resuspended with capacitation medium (modified TCM 199, pH 7.8). The concentration of spermatozoa was adjusted to $2 \times 10^{8}$ spermatozoa $\mathrm{ml}^{-1}$ and the samples were incubated in humidified air for about $3.5 \mathrm{~h}$ at $39^{\circ} \mathrm{C}$ and $5 \% \mathrm{CO}_{2}$.

\section{In vitro fertilization}

Before in vitro fertilization, cumulus-oocyte complexes were denuded mechanically using a fine glass pipette and subsequently washed in fertilization medium (TCM 199), supplemented with $0.1 \mathrm{mg}$ L-glutamine $\mathrm{ml}^{-1}, 10 \% \mathrm{FCS}, 2.0 \mathrm{mmol}$ caffeine $1^{-1}$ (Sigma) and $10 \mu \mathrm{g}$ dibekacin sulfate. During denudation, the $\mathrm{pH}$ of the medium was kept constant using a special $\mathrm{CO}_{2}$ chamber $(5 \%)$, covering the whole microscope. Oocytes were fertilized in $5 \mathrm{ml}$ fertilization medium (30 oocytes per Petri dish) containing $5 \times 10^{5}$ spermatozoa $\mathrm{ml}^{-1}$.

\section{Evaluation of events after insemination}

From 4 to $32 \mathrm{~h}$ after in vitro insemination, oocytes from both groups were fixed at $2-4 \mathrm{~h}$ intervals in acetic alcohol (1:3 v:v) and were stained $24 \mathrm{~h}$ later with aceto-orcein $(1 \% \mathrm{w} / \mathrm{v})$. The preparations were evaluated under a microscope at $\times 1200$ and the sequence of sperm penetration into the ooplasm, male and female pronucleus formation and synkaryosis were recorded. Monospermic ova were classified into six developmental categories (PN1 to PN5 plus synkaryosis) according to the criteria for bovine oocytes given by $\mathrm{Xu}$ and Greve (1988). Oocytes were classified as being normally fertilized when chromosomes, sperm head or two pronuclei with a nearby sperm tail could be identified within the ooplasm. In category PN1 the ooplasm was completely penetrated by the spermatozoon and second meiotic division had resumed. Decondensation of the chromosomes began to appear in category PN2, the sperm tail was detached and the second polar body was extruded. Category PN3 was characterized by further decondensation and the appearance of the nuclear envelope. The second polar body was located close to the female pronucleus. In category PN4 decondensation of the chromosomes was completed. The spherical pronuclei were surrounded by a complete envelope and reached maximum size in category PN5. At this time both pronuclei were close together and synkaryosis was initiated.

\section{Statistical analyses}

All experiments comprised 12 replicates involving a total of 1934 in vitro and 1124 in vivo matured oocytes. All data were tested for normal distribution (SAS Univariate procedure; SAS Institute Inc. Cary, NC). In cases of normal distribution data were analysed by the Chi square test and were considered 
Table 1. Sperm penetration rates in oocytes matured in vivo or in vitro

\begin{tabular}{lcc}
\hline Source of oocytes & $\begin{array}{c}\text { In vitro } \\
\text { matured oocytes }\end{array}$ & $\begin{array}{c}\text { In vivo } \\
\text { matured oocytes }\end{array}$ \\
\hline Total $(n)$ & 1699 & 986 \\
Penetration $(n)$ & 595 & 688 \\
Penetration (\%) & $35.0^{\mathrm{a}}$ & $69.8^{\mathrm{b}}$ \\
Monospermic $(n / n)$ & $485 / 595$ & $649 / 688$ \\
Monospermic $(\%)$ & $81.5^{\mathrm{a}}$ & $94.3^{\mathrm{b}}$ \\
Polyspermic $(n / n)$ & $110 / 595$ & $39 / 688$ \\
Polyspermic $(\%)$ & $18.5^{\mathrm{a}}$ & $5.7^{\mathrm{b}}$ \\
\hline
\end{tabular}

${ }^{\text {ah }} p<0.05$.

significant at $P<0.05$. In all other cases data were tested for significance by the Kruskal-Wallis-test (Gogolok et al., 1992). Data are presented as means \pm SEM.

\section{Results}

\section{Cumulus expansion}

Cumulus corona layers from oocytes matured in vivo were completely expanded in all the cumulus-oocyte complexes of the experiment. Similarly, in vitro matured cumulus layers were fully expanded, but the dark rim of non-expanded corona radiata was still visible in more than half of the oocytes. At the end of the maturation period, enlargement of the perivitelline space and homogeneous ooplasm were common features for oocytes of both groups.

\section{Sperm penetration}

In vivo matured cumulus-oocyte complexes had a higher $(P<0.05)$ penetration rate than in vitro matured cumulusoocyte complexes. The overall mean difference was $34.8 \%$ (Table 1). In vivo matured oocytes showed the first evidence of sperm penetration $4 \mathrm{~h}$ after insemination (Table 2). Penetration rate increased during the following $6 \mathrm{~h}$ and remained constant until the end of the observation period. In contrast, in vitro matured oocytes were first penetrated $6 \mathrm{~h}$ after insemination and reached a maximum after an additional $2 \mathrm{~h}$. This plateau remained constant until the end of the observation period but on a lower level $(35.2 \%$ versus $85.3 \%, P<0.01)$ than that of in vivo matured oocytes. The rate of polyspermy increased significantly in in vitro matured oocytes $(P<0.05$; Table 1$)$. Polygyny was observed in only eight oocytes of both groups.

\section{Pronucleus formation}

Six hours after insemination $66.0 \pm 7.8 \%$ of in vitro and $54.2 \pm 4.2 \%$ of in vivo matured oocytes were in male pronucleus stage 1 (MPN1) (Fig. 1). However, at this time, the number of in vivo matured oocytes $(45.8 \pm 4.2 \%)$ at stage MPN2 was greater than the number of in vitro matured oocytes $(13.2 \pm 5.9 \%)(P<0.05)$. In vitro matured oocytes showed a delayed sperm head decondensation of approximately $2 \mathrm{~h}$.

Within the first $6 \mathrm{~h}$ after insemination (Fig. 1) $41.7 \pm 5.6 \%$ of the in vivo matured oocytes had completed the second meiotic division (FPN2), whereas only $20.8 \pm 6.5 \%$ of the in vitro matured oocytes reached this developmental stage $(P<0.01)$. In contrast to in vivo matured oocytes, $11.1 \pm 5.9 \%$ of the in vitro matured oocytes had developed to FPN4 and $8.3 \pm 4.3 \%$ to FPN5 by this time (Figs 2 and 3 ).

Late pronuclei stages (PN4 and PN5) developed in a synchronized manner in in vivo matured oocytes (Figs 2 and 3 ).

Table 2. Time sequence of penetration and frequencies of normal and abnormal fertilization at different time intervals after insemination in vitro

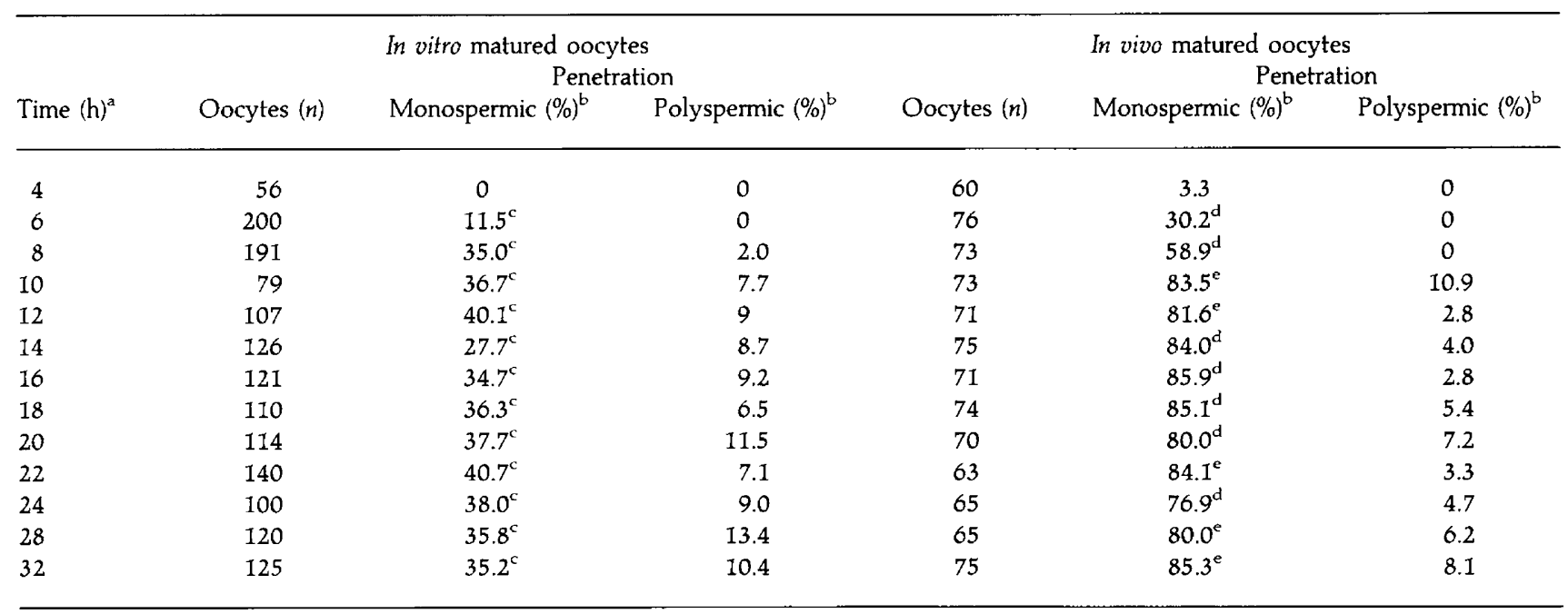

${ }^{a}$ Hour after insemination; ${ }^{b}$ calculated from all fertilized oocytes.

${ }^{c . d} P<0.05,{ }^{c . e} P<0.01$. 


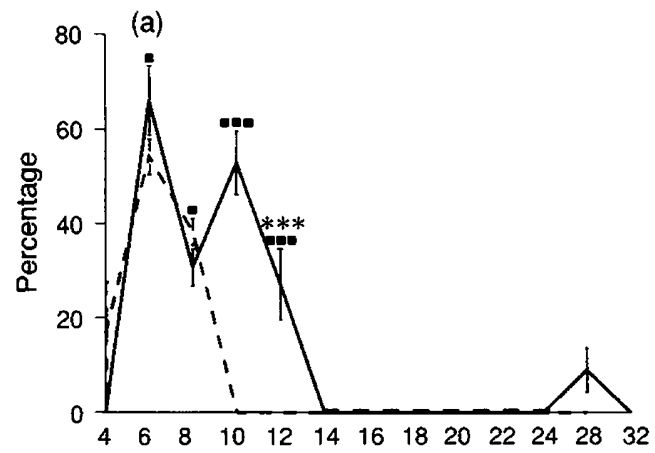

(c)

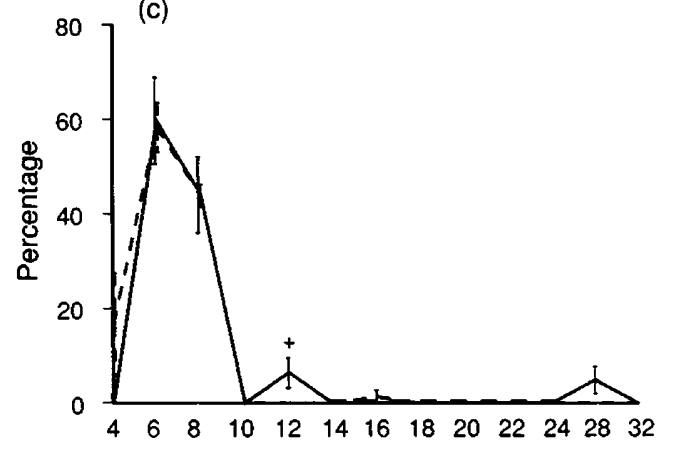

(b)

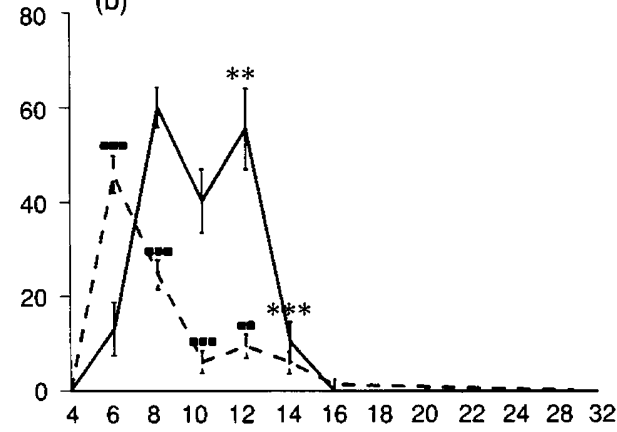

(d)

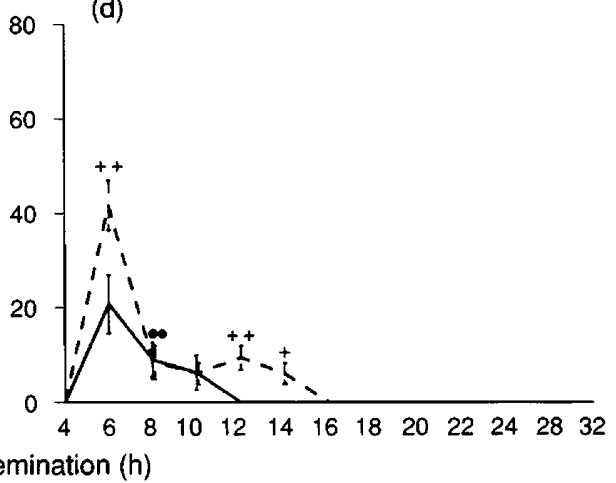

Fig. 1. (a, b) Male and (c, d) female pronucleus development ((a,c) PN1 and (b,d) PN2) of porcine oocytes matured in vitro or in vivo and fertilized in vitro. Oocytes matured in vitro $(-)$ in vivo $(---)$

Male $\mathrm{PN}$ in vitro versus in vivo Female $\mathrm{PN}$ in vitro versus in vivo Male PN versus female $P N$ in vitro Male $\mathrm{PN}$ versus female $\mathrm{PN}$ in vivo

$\begin{array}{ccc}P \leq 0.05 & 0.01 & 0.001 \\ + & * & \\ * & ++ & * * * \\ & * * & \end{array}$

Male pronucleus formation was delayed in most of the in vitro matured oocytes between 6 and $12 \mathrm{~h}$ after insemination, but was accelerated between 12 and $14 \mathrm{~h}$ and was similar to that of in vivo matured oocytes by this time (Figs 1 and 2). Both pronuclei developed in a well-synchronized manner between 16 and $32 \mathrm{~h}$ after insemination (Figs 2 and 3 ).

\section{Synkaryosis and first cleavage}

Synkaryosis (Fig. 3) was first observed $16 \mathrm{~h}$ or $18 \mathrm{~h}$ after insemination in in vivo and in vitro matured oocytes, respectively. In vivo matured oocytes reached the maximum percentage $(33.3 \%)$ of synkaryosis $20 \mathrm{~h}$ after insemination, whereas synkaryosis was delayed in in vitro matured oocytes for about $4 \mathrm{~h}$. A second peak in synkaryosis was reached in both groups after $32 \mathrm{~h}$. The percentage of synkaryosis was significantly lower $(23.9 \%$ versus $30.8 \% ; p<0.05)$ for in vivo matured oocytes because most $(52 \pm 7.3 \%)$ had already progressed to first cleavage (Fig. 3).

\section{Discussion}

The results presented in this study show that there are distinct differences in the ability of in vivo and in vitro matured pig oocytes to form female and male pronuclei and undergo first cleavage. Fertilization events were related to the onset of oestrus (Thibault, 1967), or were observed after pretreatment with hCG (Hunter, 1972) or after superovulation (Laurincik et al., 1994). Time-dependent events after fertilization in vivo were described in cows (Hyttel et al., 1988b), rabbits (Zamboni and Mastroianni, 1966) and mice (Edwards and Gates, 1959) and for the first $10 \mathrm{~h}$ after in vitro fertilization in pigs (Ding et al., 1992).

Our study provides the first comparative analysis describing the time-dependent events of pronucleus development throughout the first embryonic cell cycle in oocytes obtained from in vitro and in vivo maturation. However, results from the in vitro matured oocytes can only be related to our in vitro maturation system.

The distinct differences between in vitro and in vivo matured oocytes could be related to the lower fertilization rates after in vitro fertilization in this species compared with cattle (see Brackett and Zuelke, 1993).

In vivo fertilization is thought to occur soon after the arrival of the matured oocytes in the oviduct already harbouring capacitated spermatozoa (Thibault, 1967; Hunter, 1972; Laurincik et al., 1993, 1994). Under the conditions of our experiment, sperm penetration for in vivo matured cumulusoocyte complexes was similar to that in non-stimulated 
(a)

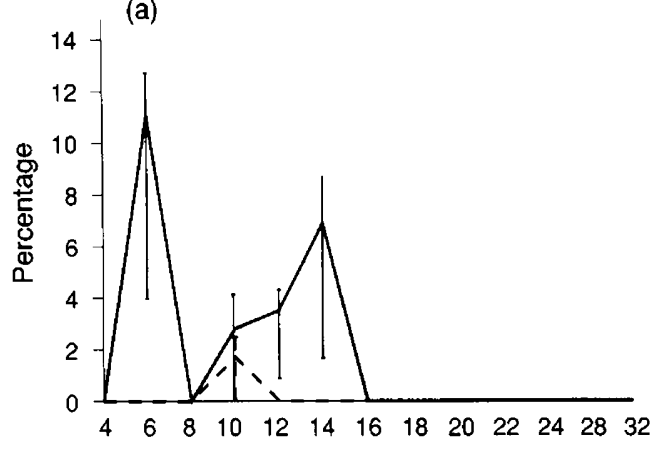

(c)

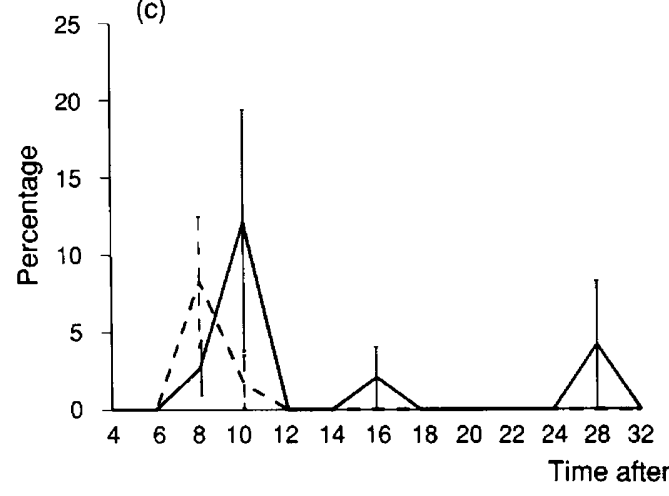

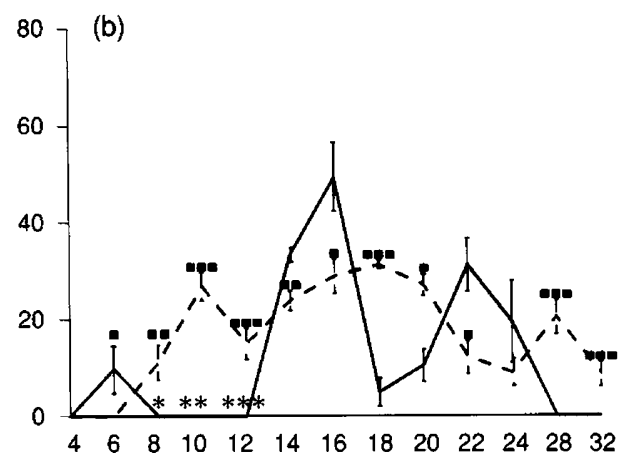

(d)

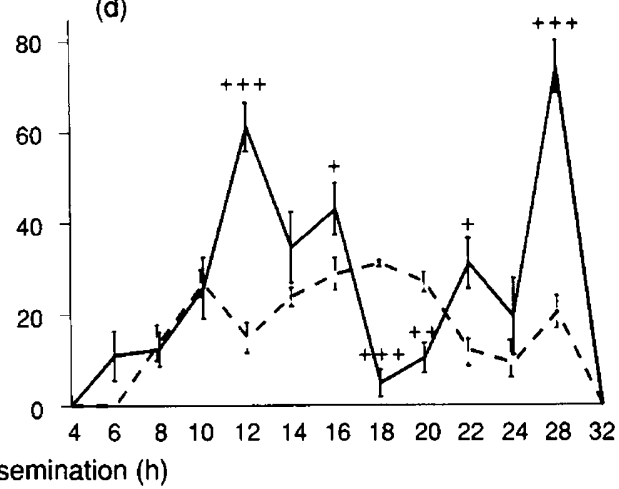

Fig. 2. (a, b) Male and (c, d) female pronucleus development $((a, c) P N 3$ and $(b, d) P N 4)$ of porcine oocytes matured in vitro or in vivo and fertilized in vitro. Oocytes matured in vitro (-) in vivo (-- $\longrightarrow$

\begin{tabular}{|c|c|c|c|}
\hline Male PN in vitro versus in vivo & $P \leq 0.05$ & $\begin{array}{c}0.01 \\
=\end{array}$ & $\begin{array}{c}0.001 \\
= \pm=\end{array}$ \\
\hline Female PN in vitro versus in vivo & + & ++ & +++ \\
\hline Male PN versus female $\mathrm{PN}$ in vitro & * & $* *$ & $* * *$ \\
\hline
\end{tabular}

(Hunter, 1972) and stimulated (Laurincik et al., 1994) gilts, demonstrating the physiological similaritiy of the three different sources of oocytes. In contrast to in vivo conditions as well as to data obtained after in vitro fertilization (Ding et al., 1992), our data show that penetration was delayed after in vitro maturation of cumulus-oocyte complexes. Since semen was prepared identically in both groups of our study, it is suggested that insufficient maturation conditions ( $\mathrm{Xu}$ and Greve, 1988) or an incomplete expanded corona layer (Laurincik et al., 1992a, b) rather than deficiencies of the spermatozoa in vitro capacitation system (Cran and Cheng, 1986) were responsible for the delay and the lower penetration rate.

After fusion of the male and female gamete, the ovum is activated and a series of nuclear changes in both the fertilizing spermatozoon and the maternal chromosomes occurs. In the oviduct (Hunter, 1972; Cran and Cheng, 1986) and under our experimental conditions, in vivo matured oocytes required $2 \mathrm{~h}$ for sperm head decondensation and an additional $2-4 \mathrm{~h}$ to develop into opposing pronuclei. This process occurred in a well-synchronized manner in both the paternal and maternal pronucleus, which is similar to findings in cattle (Hyttel et al., 1988b), hamsters (Wright and Longo, 1988) and humans (Lassalle and Testart, 1991).

A similar developmental sequence was observed after in vitro fertilization of pig oocytes by Ding et al. (1992) but no differentiation between in vivo and in vitro matured oocytes was made.

In our experiment delayed male pronucleus formation during the first $14 \mathrm{~h}$ was observed, which supports the view that the concentration of male pronucleus growth factor (MPGF) was lower in in vitro matured cumulus-oocyte complexes (Hunter, 1967; Calvin et al., 1986). For in vitro matured oocytes it was shown that female pronucleus formation was accelerated at the same time, indicating that this is independent of MPGF as suggested by Yanagimachi (1988). Male and female pronucleus development were found to be well synchronized after $16 \mathrm{~h}$, indicating that, up to this point, the male pronucleus had undergone an accelerated development. Subsequently, first cleavage in in vitro matured oocytes was delayed for $4 \mathrm{~h}$ compared with in vivo matured oocytes, suggesting that the first cell cycle was delayed.

Polyspermic penetration is one of the major causes of the failure of morphologically uniform and intact gametes to develop normally, leading to irregular early embryonic development upon syngamy (Bomsel-Helmreich, 1961; Nagai et al., 1984; Cheng, 1985; Mattioli et al., 1988b; Nagai and Moor, 1990; Wang et al., 1991; Zheng and Sirard, 1992). Excessive numbers of spermatozoa at the site of fertilization have been shown to increase the probability of polyspermic penetration (Hunter and Léglise, 1971). Cran and Cheng (1985, 1986) 

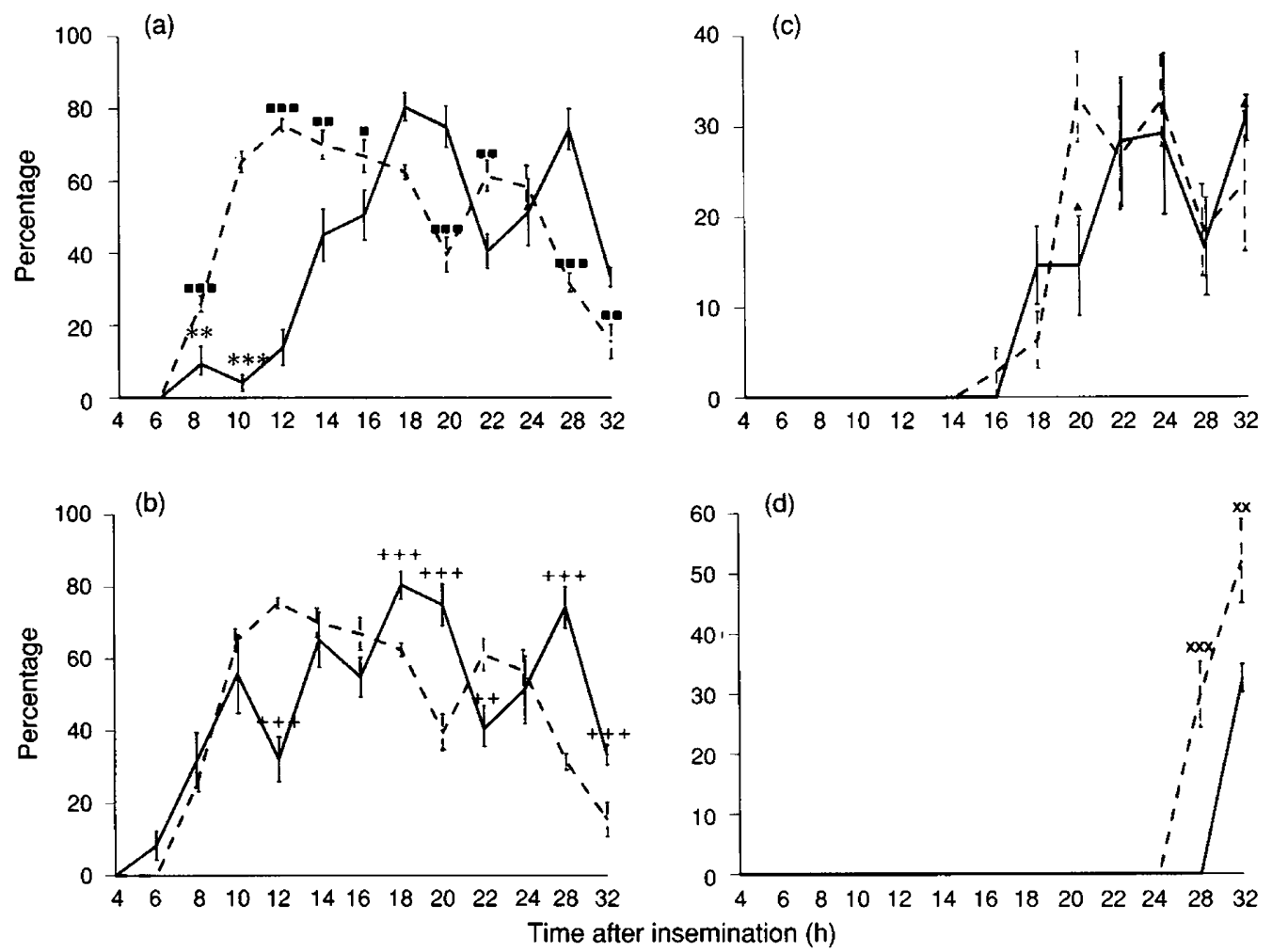

Fig. 3. (a) Male and (b) female pronucleus development (PN5), (c) synkaryosis and (d) first cleavage of in vitro and in vivo matured oocytes fertilized in vitro. Oocytes matured in vitro (-) in vivo (-- - )

Male PN in vitro versus in vivo
Female $\mathrm{PN}$ in vitro versus in vivo
Male $\mathrm{PN}$ versus female $\mathrm{PN}$ in vitro
Syngamy in vitro versus in vivo
First cleavage in vitro versus in vivo

$\begin{array}{cc}\text { vitro }(-) \text { in vivo }(---) \\ 0.01 & 0.001 \\ ++ & +++ \\ * * & * * * \\ \mathrm{XX} & \mathrm{XXX}\end{array}$

observed a higher incidence of polyspermy followed by abnormal cleavage for in vitro fertilized oocytes compared with in vivo fertilized oocytes. We showed that the reduction of the number of spermatozoa per fertilizable oocyte raises the likelihood of normal fertilization considerably (Rath, 1992). Therefore, the number of spermatozoa was reduced in our experiment and the low incidence of polyspermy resembled the physiological condition (Hunter, 1967, 1972; Laurincik et al., 1994). Our data suggest that the block against polyspermy at the level of zona or oolemma was not equally functional in in vivo and in vitro matured cumulus-oocyte complexes.

When compared with data reported earlier (Hunter, 1972), cleavage was found to be delayed by approximately 8-12 h under our experimental conditions. A similar finding was observed for in vivo matured oocytes (Yoshida, 1987) which could indicate nuclear or cytoplasmic insufficiencies (Hunter, 1990). Our results show that in vitro matured oocytes possessed less developmental competence than did in vivo matured oocytes. It has yet to be determined whether this can be attributed to the partly asynchronous pronuclei development or to a general incompetence of the ooplasm (Yoshida, 1992b).

The incidence of polygyny is mainly thought to be attributed to fertilization of immature or aged oocytes (Bedford,
1982). The time required to reach complete nuclear maturation in vitro varies considerably among immature oocytes (Sato et al., 1978; Yoshida et al., 1989) and the frequency of chromosomal abnormalities has been found to be high (McGaughey and Polge, 1971). Polygyny mainly resulting from failure of the extrusion of the first or second polar body was rarely observed in our study, indicating that the age of the oocytes was appropriate for our maturation conditions.

In summary, analysis of in vitro and in vivo matured oocytes at various times after in vitro fertilization revealed six prominent stages of early development, as defined previously in cattle ( $\mathrm{Xu}$ and Greve, 1988). Co-incubation of in vitro matured cumulus-oocyte complexes with capacitated spermatozoa resulted in lower penetration and cleavage rates, asynchronous pronucleus formation and delayed first cleavage compared with oocytes matured in vivo. It has to be noted, however, that data obtained for in vitro matured oocytes are heavily dependent on the method of maturation used and may change as culture conditions are optimized, for example, by supplementation with follicular fluid (Yoshida et al., 1992a, b).

The authors thank D. Bunke, Antje Frenzel, K.-G. Hadeler and Birgit Sieg for their skilled technical assistance. The financial 
support from the joint German-CSFR fund for agricultural research and through an Alexander von Humboldt fellowship is gratefully acknowledged.

\section{References}

Bedford JM (1982) Germ cell and fertilization. In Reproduction in Mammals pp 128-I63 Eds CR Austin and RV Short. Cambridge University Press, Cambridge

Bomsel-Helmreich O (1961) Heteroploidie expérimentale chez la truie Proceedings of the 4th International Congress on Animal Reproduction and A.I. 3 $578-581$

Brackett BG and Zuelke KA (1993) Analysis of factors involved in the in vitro production of bovine embryos Theriogenology 39 43-64

Calvin H, Grosshans K and Blake EJ (1986) Estimation and manipulation of glutathione levels in prepuberal mouse ovaries and ova: relevance to sperm nucleus transformation in the fertilized egg Gamete Research 14 265-275

Cheng WTK (1985) In vitro Fertilization of Farm Animal Oocytes. PhD Thesis, Cambridge, Council for National Academic Awards, London

Cheng WTK, Moor RM and Polge C (1986) In vitro fertilization of pig and sheep oocytes matured in vivo and in vitro Theriogenology 25 Abstract 146

Cran DG and Cheng WTK (1985) Changes in cortical granules during porcine oocyte maturation Gamete Research 11 311-319

Cran DG and Cheng WTK (1986) The cortical reaction in pig oocytes during in vivo and in vitro fertilization Gamete Research $13241-251$

Ding J and Foxcroft GR (1992) Follicular heterogeneity and oocyte maturation in vitro in pigs Biology of Reproduction 47648.655

Ding J, Clarke N, Nagai T and Moor RM (1992) Protein and nuclear changes in pig eggs at fertilization Molecular Reproduction and Development 31 287-296

Edwards RG and Gates AH (1959) Timing of the stages of the maturation, division, ovulation, fertilization and first cleavage of eggs of adult mice treated with gonadotrophins Journal of Endocrinology 18 292-304

Eng LA, Kornegay ET, Huntington J and Wellman T (1986) Effects of incubation temperature and bicarbonate on maturation of pig oocytes in vitro Joumal of Reproduction and Fertility 76 657-662

Funahashi H and Day BN (1993) Effects of the duration of exposure to supplemental hormones on cytoplasmic maturation of pig oocytes in vitro Journal of Reproduction and Fertility 98 179-185

Goglok G, Schuemer R and Ströhlein G (1992) Datenverarbeitung und statistische Auswertung mit SAS. vol. 1, pp 520-538. Gustav Fischer Verlag, Stuttgart

Hunter RHF (1967) The effect of delayed insemination on fertilization and cleavage in the pig Journal of Reproduction and Fertility 13 133-147

Hunter RHF (1972) Ovulation in the pig: timing of the response to injection of human chorionic gonadotrophin Research in Veferinary Science 13 356-361

Hunter RHF (1990) Fertilization of pig eggs in vivo and in vitro Journal of Reproduction and Fertility Supplement 40 211-226

Hunter RHF and Léglise PC (1971) Polyspermic fertilization following tubal surgery in pigs with particular reference to the role of the isthmus journal of Reproduction and Fertility $24 \quad 233-246$

Hyttel P, Xu KP and Greve T (1988a) Ultrastructural abnormalities of in vitro matured bovine oocytes Anatomy and Embryology 78 47-52

Hyttel P, Greve T and Callesen H (1988b) Ultrastructure of in-vivo fertilization in superovulated cattle Journal of Reproduction and Fertility 82 1-13

Iritani A, Niwa K and Imai H (1978) Sperm penetration of pig follicular oocytes matured in culture Journal of Reproduction and Fertility $\mathbf{5 4} 379-383$

Lassalle B and Testart J (1991) Sequential transformations of human sperm nucleus in human egg Joumal of Reproduction and Fertility 91 393-402

Laurincik J, Kroslak P, Hyttel P, Pivko J and Sirotkin AV (1992a) Bovine cumulus expansion and corona-oocyte disconnection during culture in vitro Reproduction Nutrition and Development 32 151-161

Laurincik J, Pivko J and Kroslak P (1992b) Cumulus oophorus expansion of bovine oocytes cultured in vitro: a SEM and TEM study Reproduction in Domestic Animals 27 217-228

Laurincik J, Oberfranc M, Hyttel P, Grafenau P, Tomanek M and Pivko J (1993) Characterization of the periovulatory period in superovulated heifers Theriogenology 39 537-544
Laurincik J, Hyttel P, Rath D and Pivko J (1994) Ovulation, fertilization and pronucleus development in superovulated gilts Theriogenology 41 447-452

McGaughey RW and Polge C (1971) Cytogenetic analysis of pig oocytes matured in vitro Journal of Experimental Zoology 176 383-396

Mattioli M, Galeati G, Bacci ML and Seren E (1988a) Follicular factors influence oocyte fertilizability by modulating the intercellular cooperation between cumulus cells and oocyte Gamete Research 21 223-232

Mattioli M, Galeati G and Seren E (1988b) Effect of follicle somatic cells during pig oocyte maturation on egg penetrability and male pronucleus formation Gamete Research 20 177-183

Mattioli M, Bacci ML, Galeati G and Seren E (1991) Effects of LH and FSH on the maturation of pig oocytes in vitro Theriogenology 36 95-105

Meinecke B and Meinecke-Tillmann S (1979) Effects of gonadotropins on oocyte maturation and progesterone production by porcine ovarian follicles cultured in vitro Theriogenology 11 352-365

Moor RM (1993) Prospects and problems associated with oocyte maturation in domestic animals Reproduction in Domestic Animals Supplement 2 21-22

Moor RM, Mattioli M, Ding J and Nagai T (1990) Maturation of pig oocytes in vivo and in vitro Joumal of Reproduction and Fertility Supplement 40 197-210

Motlik J and Fulka J (1974) Fertilization of pig follicular oocytes cultivated in vitro Journal of Reproduction and Fertility 36 235-237

Motlik J and Fulka J (1986) Factors affecting meiotic competence in pig oocytes Theriogenology 25 87-96

Nagai T and Moor RM (1990) Effect of oviduct cells on the incidence of polyspermy in pig eggs fertilized in vitro Molecular Reproduction and Development 26 377-382

Nagai T, Niwa K and Iritani A (1984) Effect of sperm concentration during preincubation in a defined medium on fertilization in vitro of pig follicular oocytes Journal of Reproduction and Fertility 70 271-275

Nagai T, Takahashi T, Masuda $H_{\text {t Shioya }}$, Kuwayama M, Fukushima M, Iwasaki $S$ and Hanada A (1988) In-vitro fertilization of pig oocytes by frozen boar spermatozoa Journal of Reproduction and Fertility 84 585-591

Naito K and Toyoda Y (1992) Effects of microinjection of glutathione on male pronucleus formation in porcine oocytes matured in vitro Journal of Reproduction and Fertility 38 173-178

Naito K, Fukuda Y and Toyoda Y (1988) Effects of porcine follicular fluid on male pronucleus formation in porcine oocytes matured in vitro Gamete Research 21 289-295

Niwa K (1993) Effectiveness of in vitro maturation and in vitro fertilization techniques in pigs Journal of Reproduction and Fertility Supplement $\mathbf{4 8}$ 49-59

Racowsky C and McGaughey RW (1982) In the absence of protein, estradiol suppresses meiosis of porcine oocytes in vitro Joumal of Experimental Zoology $224103-110$

Rath D (1992) Experiments to improve in vitro fertilization techniques for in vivo-matured porcine oocytes Theriogenology 37 885-896

Sato E, Iritani A and Nishikawa $Y$ (1977) Factors involved in maturation of pig and cattle follicular oocytes cultured in vitro Japanese Journal of Animal Reproduction 23 12 17

Sato E, Iritani A and Nishikawa Y (1978) Rate of maturation division of pig follicular oocytes cultured in vitro Japanese Journal of Zoology and Science $\mathbf{4 9}$ 400-405

Thibault C (1967) Analyse comparée de la fécondation et des anomalies chez la brebis, la vache et la lapine Annual of Biology. Animal Biochemistry and Biophysiology 7 5-23

Tsafriri A and Channing CP (1975) Influence of follicular maturation and culture conditions on the meiosis of pig oocytes in vitro Journal of Reproduction and Fertility 43 149-152

Tsafriri A, Pomerantz SH and Channing CP (1976) Inhibition of oocyte maturation by follicular fluid: partial characterization of the inhibitor Biology of Reproduction 14 511-516

Wang WH, Niwa K and Okuda K (1991) In-vitro penetration of pig oocytes matured in culture by frozen-thawed ejaculated spermatozoa Journal of Reproduction and Fertility 93 491-496

Wright SJ and Longo FJ (1988) Sperm nuclear enlargement in fertilized hamster eggs is related to meiotic maturation of the maternal chromatin Journal of Experimental Zoology 247 155-165

Xu KP and Greve T (1988) A detailed analysis of early events during in-vitro fertilization of bovine follicular oocytes Journal of Reproduction and Fertility 82 I27-134

Yanagimachi R (1988) Mammalian fertilization. In The Physiology of Reproduction pp 135-185 Eds E Knobil and I Neil. Raven Press, New York 
Yoshida M (1987) In vitro fertilization of pig oocytes matured in vivo Japanese Joumal of Veterinary Science 49 711-718

Yoshida M, Bamba K and Kojima Y (1989) Effects of gonadotropins and estradiol-17 beta on the timing of nuclear maturation and cumulus mass expansion in pig oocytes cultured in vitro japanese Journal of Animal Reproduction 35 86-91

Yoshida M, Ishizaki Y and Kawagishi H (1990) Blastocyst formation by pig embryos resulting from in-vitro fertilization of oocytes matured in vitro Journal of Reproduction and Fertility $\mathbf{8 8}$ 1-8

Yoshida M, Ishizaki Y, Kawagishi H, Bamba K and Kojima Y (1992a) Effects of pig follicular fluid on maturation of pig oocytes in vitro and on their subsequent fertilizing and developmental capacity in vitro journal of Reproduction and Fertility 95 481-488
Yoshida M, Ishizaki K and Pursel VG (1992b) Effect of maturation media on male pronucleus formation in pig oocytes matured in vitro Molecular Reproduction and Development 31 68-71

Yoshida M, Ishigaki K, Nagai T, Chikyu M and Pursel VG (1993) Glutathione concentration during maturation and after fertilization in pig oocytes: relevance to the ability of oocytes to form male pronucleus Biology of Reproduction 49 89-94

Zamboni L and Mastroianni L Jr (1966) Electron microscopic studies on rabbit ova II. The penetrated tubal ovum Journal of Ultrastructure Research 14 118-132

Zheng YS and Sirard MA (1992) The effect of sera, bovine serum albumin and follicular cells on in vitro maturation and fertilization of porcine oocytes Theriogenology 37 779-790 